\title{
EL RETORNO A LA DEMOCRACIA: LAS ELECCIONES GENERALES EN EL PERÚ
}

\author{
EDGAR CARPIO MARCOS
}

Profesor de Derecho Constitucional

Universidad de Lima 


\section{SUMARIO}

I. INTRODUCCIÓN. II. LA CAÍdA DEL RÉGIMEN CIVICO-MILITAR. III. DESMONTAJE DEL ORDENAMIENTO ELECTORAL DEL FUJIMORATO. IV. CONVOCATORIA Y CANDIDATURAS ELECTO-

rales. V. Campaña electoral. VI. ElecCiones PResidenciales. VII. ElecCIONES PARLAMENTARIAS. 


\title{
EL RETORNO A LA DEMOCRACIA: LAS ELECCIONES GENERALES EN EL PERÚ
}

POR

\author{
EDGAR CARPIO MARCOS \\ Profesor de Derecho Constitucional \\ Universidad de Lima
}

"La presidencia vitalicia... choca con la naturaleza y espiritu de la República. Lo que, ante todo, busca la República es la inalterable unidad de criterio entre la opinión de los gobernantes y por eso no se arriesga a entregarle su confianza para siempre. Sabe que la democracia se fatiga hasta de sus más esclarecidos servidores y no quiere exponerse a desprenderse de ellos con violencia."

(MANUel Vicente Villaran, "Ensayo sobre las ideas constitucionales de Bolívar", en Páginas Escogidas, Lima, 1962, pág. 30)

\section{INTRODUCCIÓN}

El 28 de julio de 2000, en medio de protestas públicas y acusaciones de haber sido elegido en un proceso electoral plagado de graves irregularidades ${ }^{1}$, Alberto Fujimori Fujomori juramentaba por tercera vez en el cargo de Presidente de la República.

1 Cfr. nuestra crónica "El proceso electoral peruano", en Revista de Derecho Político, n. ${ }^{\circ}$ 48-49, Madrid 2000, pág. 585 y ss. 
No podría mantenerse por mucho tiempo en el poder. Menos de dos meses después, el 16 de setiembre, en mensaje a la nación, Fujimori anunciaba su decisión de recortar su ilegítimo mandato y convocar a nuevo proceso electoral, tras hacerse públicos actos de corrupción que no sólo comprometían a su asesor, Vladimiro Montesinos Torres, un personaje siniestro, sino la propia legitimidad de su mayoría parlamentaria.

Desde entonces, los acontecimientos se fueron sucediendo a velocidad de vértigo: huyó Fujimorí del país, se declaró su permanente incapacidad moral, se censuró a la Presidenta del Congreso de la República, renunciaron los dos vicepresidentes de la República, y asumió el cargo de Presidente Constitucional de la República don Valentín Paniagua Corazao, un prestigioso político y profesor de Derecho Constitucional, en cuya gestión se desarrolló el proceso electoral del 2001.

Y si bien ha transcurrido más de un año desde los sucesos que desencadenaron el fin del régimen cívico-militar, y a la fecha no cesa de ponerse en evidencia su entraña profundamente corrupta y antidemocrática, en lo que sigue se pretende ofrecer una visión panorámica de los sucesos más importantes de las elecciones generales del 2001, que culminaron con la proclamación de Alejandro Toledo Manrique como nuevo Presidente Constitucional de la República.

\section{LA CAÍDA DEL RÉGIMEN CÍVICO-MILITAR}

El 14 de septiembre de 2000, en un hecho sin precedentes en la historia republicana, se propagaba a través de un canal de televisión cerrada la transacción entre el asesor presidencial, Vladimiro Montesinos, y un congresista electo en un movimiento político de oposición. A cambio del pago de 15,000 dólares, se acordaba su pase a las filas del oficialismo. Con el transcurso del tiempo y las investigaciones y acusaciones subsiguientes, el electorado nacional comprobaría que su decisión expresada en las urnas era traicionada por cierto sector de la clase política. No sólo se traba de un nuevo congresista que había renunciado a su movimiento para, a cambio de dinero, pasarse al fujimorismo, sino en número suficiente como para dotarle de una mayoria parlamentaria que se le había negado en las urnas.

Aunque este duro revés desencadenaría el fin del régimen autocrático, era de prever que Fujimori no duraría mucho. Las serias de- 
ficiencias de legitimidad del proceso electoral de 2000 llevaron a la Asamblea de Cancilleres de la Organización de Estados Americanos, celebrada en Canadá, a aprobar la Resolución n..$^{\circ} 1753$, por virtud de la cual se acordó enviar al Perú una misión de alto nivel, entre otros integrada por el Presidente de la OEA, con el fin de contribuir al proceso de reinstitucionalización democrática.

Dicho espacio democrático, que empezó a funcionar a partir del 21 de agosto de 2000, fecha en la que se instaló la llamada "Mesa de Diálogo y Concertación para el Fortalecimiento de la Democracia en el Perú" (bajo la dirección del Embajador de la República Dominicana, Eduardo La Torre, y con la participación de representantes del oficialismo, oposición e importantes sectores de la sociedad civill, se convirtió durante unas semanas en el centro del debate político, cuya influencia sólo terminó algunos meses después de la crisis del 14 de setiembre. Dos días después de que se propagara el vídeo de la corrupción, Fujimori anunciaba su decisión de recortar su mandato y convocar a un nuevo proceso electoral, tanto para elegir al nuevo Presidente como a los congresistas.

Sin embargo, una decisión de esta naturaleza, al no estar del todo prevista, requería de ciertas modificaciones constitucionales. Si bien la Constitución de 1993 contempla el régimen de sucesión presidencial supuesta la renuncia o declaratoria de la vacancia en el cargo presidencial, no hace lo mismo con la abreviación del mandato legislativo, el cual se prevé que es irrenunciable. Por ello, era preciso una reforma de la Constitución, lo que finalmente se hizo aprobándose la Ley de reforma constitucional . $^{\circ} 27365$, de 5 de noviembre de 2000 , por virtud de la cual se modificaba, por un lado, el artículo $112 .^{\circ}$ de la Constitución (eliminándose la reelección presidencial inmediata), y, en segundo lugar, incorporándose dos disposiciones transitorias, donde se precisaba que los plazos de los mandatos presidencial y parlamentario derivados del proceso electoral de 2000, concluirían el 28 y 26 de julio, respectivamente. Cinco dias después, mediante Decreto Supremo . $^{\circ}$ 028-2000-PCM, se convocaba a elecciones generales para el domingo 8 de abril de 2001, donde se elegiría al Presidente, los vicepresidentes y congresistas de la República.

El 15 de noviembre, con el pretexto de acudir a una invitación aceptada con antelación, Fujimori salía del país rumbo a la ciudad de Brunei y, cinco días después, enviaba su carta de renuncia desde Japón. Ésta, naturalmente, no fue aceptada. El Congreso, poco tiempo después, como antes se ha dicho, declaró la incapacidad moral de Fujimori para ejercer la Presidencia de la República. 
De acuerdo con la Constitución de 1993, si el Presidente renuncia o vaca en el cargo, el Primer Vicepresidente asume el cargo, y en defecto de éste, el Segundo Vicepresidente; y por impedimentos de ambos, el Presidente del Congreso asume el cargo de Presidente de la República y convoca de inmediato a elecciones (artículo $115 .^{\circ}$ ). La magnitud de los acontecimientos en los que se encontraba seriamente comprometido el partido de gobierno, sin embargo, impediría que los dos vicepresidentes pudieran asumir el cargo. El primer vicepresidente había renunciado días antes, $y$, horas después de renunciar Fujimori, lo propio hizo el segundo vicepresidente. La vieja caracterización que lustros atrás había formulado Mariano $\mathrm{H}$. Cornejo en torno a la institución de la vicepresidencia ("mueble viejo que nunca se usaba, salvo en casos de incendio" $)^{2}$ en esta oportunidad no serviria para salvar lo que quedaba del régimen.

Para ello, días antes se había censurado a la Presidenta del Congreso, y se había elegido a don Valentín Paniagua Corazao como nuevo titular del Poder Legislativo. El primer acto formal aprobado durante su gestión fue declarar la nulidad de las resoluciones legislativas por virtud de las cuales se destituyó a tres magistrados del Tribunal Constitucional, que años antes declararon inconstitucional la Ley de interpretación auténtica del artículo 112 de la Constitución, y por ello fueron destituidos del máximo órgano de la justicia constitucional en nuestro país ${ }^{3}$.

El 22 de noviembre de 2000, después de que el Congreso de la República aprobara la permanente incapacidad moral del Presidente de la República (Resolución Legislativa n. 009-2000-CR), asumía el más alto cargo de la República don Valentín Paniagua, en su condición de Presidente del Congreso ${ }^{4}$, de conformidad con el artículo 115 de la Constitución.

Dias después se expedía el Decreto Supremo n. ${ }^{\circ} 031-2000-P C M$, ratificándose la convocatoria a Elecciones Generales para el día 8 de

2 Cfr. Domingo García BeLAUnde, Teoría y práctica de la constitución peruana, t. 2, Ediciones Justo Valenzuela, Lima, 1993, pág. 252.

3 Cfr. Edgar Carpio Marcos, "Constitución y reelección presidencial (El caso peruano)" ", en Boletín Mexicano de Derecho Comparado, n. ${ }^{\circ}$ 98, UNAM, México, 2000.

4 El debate sobre si en su condición de Presidente de la República había dejado de ser Presidente del Congreso terminó, en el plano político, con la expedición de la Ley $n:^{\circ} 27375$, por virtud de la cual se interpretaba el artículo 115 de la Constitución en el sentido de que la asunción del despacho presidencial no implicaba la vacancia de su cargo de Presidente de la República. 
abril de 2001. Como era natural, para que dicho proceso electoral pudiera realizarse de manera transparente, era preciso desmontar el aparato institucional y legal utilizado por el fujimorismo para reelegirse por tercera vez consecutiva, lo que se consideraba como una de las condiciones básicas y primordiales para asegurar la legitimidad del nuevo proceso electoral.

\section{DESMONTAJE DEL ORDENAMIENTO ELECTORAL DEL FUJIMORATO}

La primera condición para que el proceso electoral a realizarse el 8 de abril de 2001 no pudiera ser tachado de ilegítimo, era desmontar el ordenamiento electoral del que se había valido el fujimorato para manejar a los órganos públicos encargados de su realización ${ }^{5}$. Por ello, aun antes de que se instalase el Gobiemo de Transición presidido por Valentín Paniagua, derivado del acuerdo adoptado en la Mesa de Diálogo promovido por la OEA, se promulgaba la Ley $n .^{\circ} 27369$, por virtud de la cual se realizaron importantes reformas a la legislación electoral. Entre los aspectos más relevantes, cabe mencionar:

- Autorizar a la Oficina Nacional de Procesos Electorales a realizar el sorteo de nuevos miembros de mesa.

- Reconocer la vigencia de la inscripción de los partidos y alianzas políticas, con el único requisito de haber obtenido representación parlamentaria en el proceso electoral de 2000.

- Ampliar la competencia de los personeros técnicos para observar en tiempo real los procesos de cómputo relacionados con su circunscripción.

- Limitar la difusión de las encuestas a boca de urna hasta después de que la Oficina Nacional de Procesos Electorales difunda el primer conteo rápido o a partir de las 22 horas, lo que ocurra primero.

- Reducir el plazo de prohibición de la difusión de encuestas electorales (de dos semanas a una).

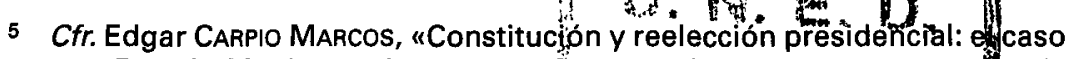
peruano", en Boletín Mexicano de Derecho Compąado, n.: 98, mayo-agoja de 2000 , págs. 447 y ss. 
- Garantizar la imparcialidad informativa del Estado

- Establecer una franja electoral, habilitándose espacio en los canales de televisión de señal abierta y estaciones de radio, públicos o privados, de cobertura nacional.

- Variar el perverso sistema de votación del Jurado Nacional de Elecciones, dictado con el propósito de evitar que el máximo órgano de justicia electoral resolviera con independencia tachas e impugnaciones.

Con posterioridad, y dentro del marco de reformas a la legislación electoral, después de titubeos y un inicial rechazo en el Congreso, se promulgó la Ley $n .^{\circ} 27387$, en la que se establecía que la elección de los congresistas en el próximo proceso electoral de 2001 sería por el sistema de distrito electoral múltiple, y no ya en distrito electoral único, como se hizo en el proceso electoral anterior. Se establecieron 25 distritos electorales, entre ellos el de la Provincia Constitucional del Callao. Asimismo, se amplió la cuota electoral (de mujeres, y eventualmente de varones) al $30 \%$ de cada lista.

Paralelamente, se abrieron canales para expectorar a las autoridades electorales en cuya responsabilidad recayó la realización del proceso electoral de 2000. Durante el fujimorato los representantes de los órganos electorales debieron su elección a la aplicación de leyes exprofesamente dictadas con el objeto de coparlas. Por ello, y en la medida que la crisis política se resolvía con la instauración de un nuevo gobierno, personajes cuestionados por encontrarse identificados con el régimen pasado optaron por renunciar a sus cargos, entre ellos los representantes del Poder Judicial y el Ministerio Público ante el Jurado Nacional de Elecciones, donde el primero de ellos fungía de Presidente.

Con la elección de los nuevos representantes de estos dos órganos del Estado, a los que se sumó ta renovación de otros dos representantes del Jurado Nacional de Elecciones, se garantizaba la autonomía e imparcialidad de este importante órgano electoral, lo que no precisamente se había observado en la última elección ${ }^{6}$.

Asimismo, el Consejo Nacional de la Magistratura, cuyas atribuciones cercenadas por el fujimorismo las había recobrado, por deci-

6 Cfr. María Vicenta GARCía SORIANo, Jueces y magistrados en el proceso electoral, CEPC, Madrid, 2000. 
sión unánime destituía al Jefe de la Oficina Nacional de Procesos Electorales, cuya gestión fue seriamente cuestionada 7 . En su reemplazo se nombraba a Fernando Tuesta Soldevilla, un profesor universitario de prestigio, a quien se le confiaba la realización de un proceso electoral en tan breve tiempo, lo que le exigía, previamente, exorcizar a su institución.

Con esta nueva conformación de los órganos electorales y la derogación de la legislación de la que se había valido el régimen anterior para reelegirse inconstitucionalmente por tercera vez, la población adquirió nuevamente confianza en que esta vez las votaciones traducirían la expresión auténtica, libre y espontánea de los ciudadanos.

\section{CONVOCATORIA Y CANDIDATURAS ELECTORALES}

Como ya se ha indicado, por Decreto Supremo n. ${ }^{\circ}$ 028-2000$\mathrm{PCM}$, ratificado por el Decreto Supremo n. ${ }^{\circ} 031-2000-\mathrm{PCM}$, se convocó a elecciones generales para el 8 de abril de 2001. El primero de los decretos, asimismo, disponía que en caso de que ninguno de los candidatos a la Presidencia de la República y Vicepresidentes obtuviese más de la mitad de los votos válidos, se procedería a una segunda elección entre los dos candidatos que hubiesen obtenido la votación más alta, dentro de los treinta días siguientes a la proclamación de los cómputos oficiales.

Dentro del plazo legal, solicitaron su inscripción para participar en el proceso electoral los siguientes partidos y alianzas políticas: Alianza Electoral Unidad Nacional, Partido Aprista Peruano, Frente Independiente Moralizador, Alianza Electoral Solución Popular, Partido Renacimiento Andino, Partido Proyecto País y Todos por la Victoria.

En lo que a las elecciones parlamentarias se refiere, que, como se ha anticipado, se realizarían simultáneamente a las presidenciales, la modificación de la elección del sistema electoral único, por el sistema electoral múltiple, propició que en los veinticinco distritos electorales se presentaran, aparte de las alianzas y partidos con candidatos a la presidencia de la República, una serie de movimientos políticos

7 Cfr. Defensoría del Pueblo, Elecciones 2001. Informe de supervisión de la Defensoría del Pueblo, Lima, 2001. 
regionales, lo que a la par de haber motivado la democratización de la elección de los representantes ante el Congreso, ha hecho que el sistema devenga en más complejo.

\section{CAMPAÑA ELECTORAL}

A diferencia de lo sucedido en 2000, la campaña electoral en 2001 se desarrolló con respeto a las garantías electorales indispensables para que un proceso electoral pueda ser considerado como constitucionalmente aceptable ${ }^{8}$. Por un lado, la expedición de la Ley $n .^{\circ} 27369$ permitió que los diversos candidatos, haciendo uso de la franja electoral, pudieran trasmitir los programas y políticas públicas que implementarían en caso de que accedieran a los cargos de representación política a los que postulaban. De otro lado, la imparcialidad informativa del Estado propició que ninguno de los candidatos se viera beneficiado desde el poder.

A fin de evitar cualquier tipo de interferencia de los diversos sectores de la Administración estatal en el proceso electoral, el gobiemo central expidió el Decreto Supremo n. ${ }^{\circ}$ 004-2001-PCM, por virtud del cual se aprobaba la "Directiva sobre neutralidad y transparencia de los organismos, funcionarios y servidores públicos del Poder Ejecutivo durante el proceso electoral del año 2001 ".

En el ámbito de la campaña presidencial, hay que señalar dos factores que marcarían todo este período, y en cierta forma se reflejarían en el resultado de la primera vuelta.

Por un lado, fue opacada por la difusión de una serie de vídeos donde se observaba la manera como se manipuló a los diversos órganos del Estado y a sus principales representantes. En este contexto, como es obvio, el plano programático pasó a un segundo plano, y la atención principal se centró en la reivindicación de la moral y la ética para el acceso a los cargos públicos, así como en denuncias -que en modo alguno, podían considerarse como parte de una guerra suciasobre la composición de algunas alianzas políticas, en el sentido de que mantenían, entre sus asesores y candidatos al Congreso, perso-

8 Cfr. las importantes reflexiones de Artemi Rallo LombarTe, Garantias electorales y Constitución, CEPC, Madrid, 1997, especialmente, págs. 27 y ss. 
najes -en su mayor parte de nivel medio- que colaboraron con el régimen anterior. No faltaron también denuncias, a nuestro juicio exageradas, de haberse utilizado la difusión de los vídeos para perjudicar a algunos candidatos y alianzas políticas.

Un factor importante, que en cierto modo cambió el escenario de la campaña, aconteció con la postulación del ex-presidente García Pérez y la introducción en el discurso electoral de la necesidad de ciertas medidas de orden social. Hasta entonces, el debate esencialmente giraba en el mantenimiento de un fujimorismo económico sin Fujimori. Con su presencia, la campaña adquirió un nuevo perfil, que, unido a su carisma, logró que se revirtiera toda una década de satanización, que lo había condenado al exilio desde abril de 1992.

Como en todo proceso electoral, aunque no sea lo deseable, no faltaron expresiones de intolerancia. Vistas en perspectiva, nada relevantes, sin embargo, como para desacreditar el proceso electoral.

Un tema importante que se suscitó en plena campaña electoral fue la interposición por el Defensor del Pueblo de la acción de inconstitucionalidad (el recurso directo) contra el segundo párrafo del artículo 191 de la Ley Orgánica Electoral. Dicho precepto, que fue acordado por los sectores con representación en la Mesa del Diálogo promovida por la Organización de Estados Americanos, se introdujo con el objeto de impedir que la difusión de las encuestas a boca de urna, una vez culminado el proceso electoral, pudiera generar los mismos problemas que se presentaron durante la segunda vuelta en el proceso electoral de 2000. Esencialmente se consideró que dicho precepto era inconstitucional, pues impedía que la población pudiera tener, una vez culminadas las elecciones, acceso a la información sobre los resultados electorales. Tres días antes de que se llevaran a cabo las elecciones, el Tribunal Constitucional, probablemente en la sentencia más rápida que se haya expedido en todos estos años de funcionamiento, haría público su pronunciamiento, declarando su inconstitucionalidad, si bien por razones del todo ajenas a las planteadas en el proceso por las partes ${ }^{9}$.

9 Permítasenos la remisión a un trabajo nuestro, "Cuestiones marginales (y marginadas) en la sentencia del Tribunal Constitucional sobre las encuestas a boca de urna", en Diálogo con la Jurisprudencia, n. ${ }^{\circ} 33$, Lima, 2001 , págs. 91 y ss. 


\section{ELECCIONES PRESIDENCIALES}

De acuerdo con el artículo $111 .^{\circ}$ de la Constitución, el Presidente de la República se elige por sufragio directo. Es elegido entre el candidato que obtiene más de la mitad de los votos, para lo cual no se computan ni los viciados ni en blanco. $Y$ de no obtener ninguno la mayoría absoluta, se procede a una segunda elección, dentro de los treinta días siguientes a la proclamación de los cómputos oficiales, entre los candidatos que hayan obtenido las dos más altas mayorías relativas. El proceso electoral, fijado para realizarse el 8 de abril de 2001, empezó a las 8 a.m. y culminó a las 4 p.m.

Como era previsible, al culminar la primera vuelta, y según daban cuenta las primeras encuestas a boca de urna que se difundieron, el ganador fue el candidato Alejandro Toledo, quien habia alcanzado la primera mayoría relativa, y durante el proceso electoral de 2000 se había convertido en el principal líder de la oposición democrática.

Las primeras informaciones, sin embargo, no brindaban certeza sobre el candidato que ocuparía el segundo lugar de las preferencias electorales, y de ese modo participaría en la segunda vuelta. Después de la difusión de los primeros conteos basados en el muestreo de actas electorales, éste arrojó como segundo en las preferencias al ex-presidente García Pérez, candidato del Partido Aprista Peruano, quien había retornado al país, después de un largo exilio de 8 años, con no más de 3 meses de antelación. En tanto que el tercer lugar, como puede observarse del cuadro $n .^{\circ} 1$ y por ligero margen de diferencia, era ocupado por la candidata de la Alianza Electoral Unidad Nacional, Lourdes Flores Nano. 
ELECCIONES PRESIDENCIALES (PRIMERA VUELTA)

\begin{tabular}{lcc}
\hline $\begin{array}{c}\text { Organizaciones políticas que } \\
\text { presentaron fórmula presidencial }\end{array}$ & Total de votos & Porcentaje (\%) \\
\hline Partido Perú Posible & 3.871 .167 & 36,51 \\
\hline Alianza Electoral Unidad Nacional & 2.576 .653 & 24,30 \\
\hline Partido Aprista Peruano & 2.732 .857 & 25,78 \\
\hline Frente Independiente Moralizador & 1.044 .207 & 9,85 \\
\hline Alianza Electoral Solución Popular & 179.243 & 1,69 \\
\hline Partido Renacimiento Andino & 85.436 & 0,81 \\
\hline Partido Proyecto Pais & 70.077 & 0,75 \\
\hline Todos por la Victoria & 33.080 & 0,31 \\
\hline Total de votos emitidos & 12.264 .349 & \\
\hline \multicolumn{2}{c}{ Votos en blanco } & 1.260 .193 \\
\hline Votos nulos & 402.436 \\
\hline
\end{tabular}

Fuente: Jurado Nacional de Elecciones.

Resolución n. ${ }^{\circ}$ 473-2001-JNE.

Casi un mes y medio después de que se realizara el proceso electoral, el 21 de mayo de 2001, la Oficina Nacional de Procesos Electorales terminaba con realizar el cómputo nacional de los votos $y$, al día siguiente, el Jurado Nacional de Elecciones convocaba oficialmente a Segunda Vuelta, que se llevaría a cabo el domingo 3 de junio de 2001.

Pese al retraso en la oficialización de los resultados de la primera vuelta, no imputables a la ONPE, ello no había impedido que la campaña entre los dos candidatos más votados prosiguiera. A diferencia de la primera vuelta, esta vez el electorado tuvo mejores posibilidades de poder conocer los planes de gobiemo de los aspirantes al sillón presidencial. Se realizó un debate entre los dos candidatos, que fue televisado a nivel nacional, aparte de tomarse nuevamente las plazas públicas para difundirse los planes de gobierno.

El 3 de junio el proceso electoral se iniciaría a las 8 a.m., y terminaría a las 4 p.m. Los resultados oficiales, que no tardarían tanto como en la primera vuelta, fueron hechos públicos el 13 de junio de 2001. Éstos son: 
ELECCIÓN PRESIDENCIAL (SEGUNDA VUELTA)

\begin{tabular}{lcc}
\hline Organizaciones politicas & Total de votos & Porcentaje (\%) \\
\hline Partido Perú Posible & 5.548 .556 & 53,08 \\
\hline Partido Aprista Peruano & 4.904 .929 & 46,92 \\
\hline Total de votos válidos & 10.453 .485 & 100,00 \\
\hline Votos en blanco & 333.546 & \\
\hline Votos nulos & 1.341 .938 & \\
\hline Total votos emitidos & 12.128 .969 & \\
\hline Electores hábiles & 14.906 .233 & \\
\hline
\end{tabular}

Fuente: Jurado Nacional de Elecciones.

Resolución n. ${ }^{\circ}$ 504-2001-JNE.

De esta forma, el Jurado Nacional de Elecciones proclamaba como ganadores de la segunda vuelta a la Lista del Partido Perú Posible, encabezada por don Alejandro Toledo Manrique como Presidente, y Raúl Díez Canseco Terry y David Waisman como Vicepresidentes. Terminaba así un largo proceso electoral que en menos de 2 años había convocado a los peruanos a las urnas.

\section{ELECCIONES PARLAMENTARIAS}

Simultáneamente con la elección presidencial, se llevaron adelante las elecciones parlamentarias. Salvo la variación del distrito electoral único por la elección mediante el distrito electoral múltiple, en lo demás se aplicaron las mismas reglas que se utilizaron en el proceso electoral de 2000; esto es, se elegirían 120 congresitas (Congreso Unicameral), de acuerdo con un sistema de representación proporcional, que se obtiene mediante el método de la "cifra repartidora".

A continuación, a costa de ampliar innecesariamente el espacio de esta breve reseña, se consignan los cuadros de los resultados por cada distrito electoral. 


\section{Distrito Electoral de Amazonas}

\begin{tabular}{lrc}
\hline & Total de votos & Porcentaje (\%) \\
\hline Alianza Electoral Unidad Nacional & 14.231 & 15,40 \\
\hline Frente Independiente Moralizador & 3.380 & 3,66 \\
\hline Frente Popular Agrícola FIA del Perú & 334 & 0,36 \\
\hline Movimiento Independiente Somos Perú & 8.931 & 9,67 \\
\hline Partido Renacimiento Andino & 1.355 & 1,47 \\
\hline Partido Acción Popular & 6.320 & 6,84 \\
\hline Partido Aprista Peruano & 16.804 & 18,19 \\
\hline Todos por la Victoria & 7.708 & 8,34 \\
\hline Alianza Electoral Solución Popular & 2.995 & 3,24 \\
\hline Partido Perú Posible. & 24.734 & 26,77 \\
\hline Partido Proyecto País & 5.164 & 5,59 \\
\hline Alianza Electoral Cambio 90-Nueva Mayoría & 427 & 0,46 \\
\hline Total votos válidos & 92.383 & \\
\hline$\quad$ Votos en blanco & 13.032 & \\
\hline \multicolumn{2}{c}{ Votos nulos } & 18.686 \\
\hline Total votos emitidos & 124.101 & \\
\hline
\end{tabular}

\section{Distrito Electoral de Ancash}

\begin{tabular}{lcc}
\hline & Total de votos & Porcentaje (\%) \\
\hline Alianza Electoral Unidad Nacional & 37.005 & 10,53 \\
\hline Frente Independiente Moralizador & 42.806 & 12,18 \\
\hline Frente Popular Agrícola FIA del Perú & 5.041 & 1,43 \\
\hline Movimiento Independiente Somos Perú & 10.895 & 3,10 \\
\hline Partido Renacimiento Andino & 5.477 & 1,56 \\
\hline Partido Acción Popular & 5.915 & 1,68 \\
\hline Partido Aprista Peruano & 85.674 & 24,38 \\
\hline Agrupación Independiente Unión por el Perú- & & 2,60 \\
\hline Social Democracia & 9.124 & 0,40 \\
\hline Todos por la Victoria & 1.408 & 1,29 \\
\hline Alianza Electoral Solución Popular & 4.546 & 37,66 \\
\hline Partido Perú Posible & 132.331 & 1,11 \\
\hline Partido Proyecto País & 3.911 & 2,06 \\
\hline Alianza Electoral Cambio 90-Nueva Mayoría & 7.246 & \\
\hline Total votos válidos & 351.379 & \\
\hline$\quad$ Votos en blanco & 64.903 & \\
\hline$\quad$ Votos nulos & 51.892 & \\
\hline Total votos emitidos & 468.174 & \\
\hline
\end{tabular}




\section{Distrito Electoral de Apurímac}

\begin{tabular}{lcc}
\hline & Total de votos & Porcentaje (\%) \\
\hline Alianza Electoral Unidad Nacional & 10.139 & 10,87 \\
\hline Frente Independiente Moralizador & 5.604 & 6,01 \\
\hline Frente Popular Agrícola FIA del Perú & 1.960 & 2,10 \\
\hline Movimiento Independiente Somos Perú & 5.568 & 5,97 \\
\hline Partido Renacimiento Andino & 860 & 0,92 \\
\hline Partido Acción Popular & 1.793 & 1,92 \\
\hline Partido Aprista Peruano & 9.193 & 9,86 \\
\hline Agrupación Independiente Unión por el Perú- & 18.653 & 20,00 \\
\hline Social Democracia & 1.085 & 1,16 \\
\hline Todos por la Victoria & 7.387 & 7,92 \\
\hline Alianza Electoral Solución Popular & 27.916 & 29,93 \\
\hline Partido Perú Posible & 1.456 & 1,56 \\
\hline Partido Proyecto País & 1.657 & 1,78 \\
\hline Alianza Electoral Cambio 90-Nueva Mayoria & 93.271 & \\
\hline Total votos válidos & 21.457 & \\
\hline Votos en blanco & 23.781 & \\
\hline Votos nulos & 138.509 & \\
\hline Total votos emitidos & \\
\hline
\end{tabular}

\section{Distrito Electoral de Arequipa}

\begin{tabular}{lrc}
\hline & Total de votos & Porcentaje (\%) \\
\hline Alianza Electoral Unidad Nacional & 48.128 & 9,88 \\
\hline Frente Independiente Moralizador & 54.731 & 11,23 \\
\hline Frente Popular Agrícola FIA del Perú & 7.171 & 1,47 \\
\hline Movimiento Independiente Somos Perú & 39.999 & 8,21 \\
\hline Partido Renacimiento Andino & 7.336 & 1,51 \\
\hline Partido Acción Popular & 31.190 & 6,40 \\
\hline Partido Aprista Peruano & 90.316 & 18,54 \\
\hline Agrupación Independiente Unión por el Perú- & 13.149 & 2,70 \\
\hline Social Democracia & 6.480 & 1,33 \\
\hline Todos por la Victoria & 35.614 & 7,31 \\
\hline Alianza Electoral Solución Popular & 132.806 & 27,26 \\
\hline Partido Perú Posible & 12.300 & 2,52 \\
\hline Partido Proyecto País & 8.024 & 1,65 \\
\hline Alianza Electoral Cambio 90-Nueva Mayoría & 487.244 \\
\hline Total votos válidos & 51.520 & \\
\hline Votos en blanco & 58.821 & \\
\hline Votos nulos & 597.585 & \\
\hline Total votos emitidos & \\
\hline
\end{tabular}




\section{Distrito Electoral de Ayacucho}

\begin{tabular}{lrc}
\hline & Total de votos & Porcentaje (\%) \\
\hline Alianza Electoral Unidad Nacional & 23.921 & 16,72 \\
\hline Frente Independiente Moralizador & 11.112 & 7,77 \\
\hline Frente Popular Agrícola FIA del Perú & 5.195 & 3,63 \\
\hline Movimiento Independiente Somos Perú & 1.065 & 0,74 \\
\hline Partido Renacimiento Andino & 3.336 & 2,33 \\
\hline Partido Acción Popular & 3.395 & 2,37 \\
\hline Partido Aprista Peruano & 23.359 & 16,33 \\
\hline Agrupación Independiente Unión por el Perú- & & \\
$\quad$ Social Democracia & 7.212 & 5,04 \\
\hline Todos por la Victoria & 4.761 & 3,33 \\
\hline Alianza Electoral Solución Popular & 4.958 & 3,47 \\
\hline Partido Perú Posible & 47.034 & 32,87 \\
\hline Partido Proyecto Pais & 4.136 & 2,89 \\
\hline Alianza Electoral Cambio 90-Nueva Mayoria & 3.598 & 2,51 \\
\hline Total votos válidos & 143.082 & \\
\hline$\quad$ Votos en blanco & 35.935 & \\
\hline$\quad$ Votos nulos & 31.620 \\
\hline Total votos emitidos & 210.637 & \\
\hline
\end{tabular}

\section{Distrito Electoral de Cajamarca}

\begin{tabular}{lrr}
\hline & Total de votos & Porcentaje (\%) \\
\hline Alianza Electoral Unidad Nacional & 90.461 & 24,68 \\
\hline Frente Independiente Moralizador & 51.041 & 13,92 \\
\hline Frente Popular Agrícola FIA del Perú & 831 & 0,23 \\
\hline Movimiento Independiente Somos Perú & 4.286 & 1,17 \\
\hline Partido Renacimiento Andino & 6.843 & 1,87 \\
\hline Partido Acción Popular & 22.500 & 6,14 \\
\hline Partido Aprista Peruano & 56.169 & 15,32 \\
\hline Agrupación Independiente Unión por el Perú- & 10.512 & 2,87 \\
\hline Social Democracia & 4.123 & 1,12 \\
\hline Todos por la Victoria & 14.230 & 3,88 \\
\hline Alianza Electoral Solución Popular & 98.102 & 26,76 \\
\hline Partido Perú Posible & 4.053 & 1,11 \\
\hline Partido Proyecto País & 3.434 & 0,94 \\
\hline Alianza Electoral Cambio 90-Nueva Mayoría & 366.585 \\
\hline Total votos válidos & 63.272 \\
\hline$\quad$ Votos en blanco & 57.467 \\
\hline$\quad$ Votos nulos & 487.324 \\
\hline Total votos emitidos & \\
\hline
\end{tabular}




\section{Distrito Electoral del Callao}

\begin{tabular}{lrc}
\hline & Total de votos & Porcentaje (\%) \\
\hline Alianza Electoral Unidad Nacional & 37.759 & 12,15 \\
\hline Frente Independiente Moralizador & 37.669 & 12,12 \\
\hline Frente Popular Agrícola FIA del Perú & 2.511 & 0,81 \\
\hline Movimiento Independiente Somos Perú & 19.152 & 6,16 \\
\hline Partido Renacimiento Andino & 4.011 & 1,29 \\
\hline Partido Acción Popular & 3.736 & 1,20 \\
\hline Partido Aprista Peruano & 78.062 & 25,12 \\
\hline Agrupación Independiente Unión por el Perú- & 3.226 & 1,04 \\
\hline Social Democracia & 14.967 & 4,82 \\
\hline Todos por la Victoria & 7.125 & 2,29 \\
\hline Alianza Electoral Solución Popular & 80.359 & 25,86 \\
\hline Partido Perú Posible & 6.818 & 2,19 \\
\hline Partido Proyecto País & 15.325 & 4,93 \\
\hline Alianza Electoral Cambio 90-Nueva Mayoría & 310.720 \\
\hline Total votos válidos & 36.048 \\
\hline$\quad$ Votos en blanco & 51.076 \\
\hline$\quad$ Votos nulos & 397.844 \\
\hline Total votos emitidos
\end{tabular}

\section{Distrito Electoral del Cusco}

\begin{tabular}{lrc}
\hline & Total de votos & Porcentaje (\%) \\
\hline Alianza Electoral Unidad Nacional & 27.967 & 8,26 \\
\hline Frente Independiente Moralizador & 22.300 & 6,59 \\
\hline Frente Popular Agrícola FIA del Perú & 5.268 & 1,56 \\
\hline Movimiento Independiente Somos Perú & 34.702 & 10,25 \\
\hline Partido Acción Popular & 5.889 & 1,74 \\
\hline Partido Aprista Peruano & 38.815 & 11,46 \\
\hline Agrupación Independiente Unión por el Perú- & 45.200 & 13,35 \\
\hline Social Democracia & 38.626 & 11,41 \\
\hline Todos por la Victoria & 4.350 & 1,28 \\
\hline Alianza Electoral Solución Popular & 110.951 & 32,77 \\
\hline Partido Perú Posible & 4.521 & 1,34 \\
\hline Alianza Electoral Cambio 90-Nueva Mayoría & 338.589 \\
\hline Total votos válidos & 51.494 \\
\hline$\quad$ Votos en blanco & 77.338 \\
\hline$\quad$ Votos nulos & 467.421 \\
\hline Total votos emitidos & \\
\hline
\end{tabular}




\section{Distrito Electoral de Huancavelica}

\begin{tabular}{lcc}
\hline & Total de votos & Porcentaje (\%) \\
\hline Alianza Electoral Unidad Nacional & 18.605 & 17,99 \\
\hline Frente Independiente Moralizador & 10.970 & 10,61 \\
\hline Frente Popular Agrícola FIA del Perú & 3.966 & 3,84 \\
\hline Movimiento Independiente Somos Perú & 3.416 & 3,30 \\
\hline Partido Renacimiento Andino & 9.380 & 9,07 \\
\hline Partido Acción Popular & 6.350 & 6,14 \\
\hline Partido Aprista Peruano & 9.456 & 9,14 \\
\hline Agrupación Independiente Unión por el Perú- & & \\
Social Democracia & 2.961 & 2,86 \\
\hline Todos por la Victoria & 3.214 & 3,11 \\
\hline Alianza Electoral Solución Popular & 2.857 & 2,76 \\
\hline Partido Perú Posible & 25.620 & 24,78 \\
\hline Partido Proyecto País & 4.126 & 3,99 \\
\hline Alianza Electoral Cambio 90-Nueva Mayoría & 2.480 & 2,40 \\
\hline Total votos válidos & 103.401 & \\
\hline$\quad$ Votos en blanco & 25.416 & \\
\hline \multicolumn{2}{r}{ Votos nulos } & 24.114 \\
\hline Total votos emitidos & 152.931 & \\
\hline
\end{tabular}

10. Distrito Electoral de Huánuco

\begin{tabular}{lrc}
\hline & Total de votos & Porcentaje (\%) \\
\hline Alianza Electoral Unidad Nacional & 38.743 & 21,39 \\
\hline Frente Independiente Moralizador & 12.070 & 6,66 \\
\hline Frente Popular Agrícola FlA del Perú & 5.562 & 3,07 \\
\hline $\begin{array}{l}\text { Movimiento Independiente Somos Perú- } \\
\text { Causa Democrática }\end{array}$ & 17.627 & 9,73 \\
\hline Partido Renacimiento Andino & 1.135 & 0,63 \\
\hline Partido Acción Popular & 8.126 & 4,49 \\
\hline Partido Aprista Peruano & 21.546 & 11,90 \\
\hline Agrupación Independiente Unión por el Perú- & 10.077 & 5,56 \\
\hline Social Democracia & 6.021 & 3,32 \\
\hline Todos por la Victoria & 1.643 & 0,91 \\
\hline Alianza Electoral Solución Popular & 51.853 & 28,63 \\
\hline Partido Perú Posible & 4.877 & 2,69 \\
\hline Partido Proyecto País & 1.844 & 1,02 \\
\hline Alianza Electoral Cambio 90-Nueva Mayoría & 181.124 \\
\hline Total votos válidos & 31.689 \\
\hline$\quad$ Votos en blanco & 36.326 \\
\hline$\quad$ Votos nulos & 249.139 \\
\hline Total votos emitidos
\end{tabular}




\section{Distrito Electoral de Ica}

\begin{tabular}{lcc}
\hline & Total de votos & Porcentaje (\%) \\
\hline Alianza Electoral Unidad Nacional & 31.118 & 10,61 \\
\hline Frente Independiente Moralizador & 37.284 & 12,72 \\
\hline Frente Popular Agrícola FIA del Perú & 2.516 & 0,86 \\
\hline Movimiento Independiente Somos Perú & 4.987 & 1,70 \\
\hline Partido Renacimiento Andino & 3.677 & 1,25 \\
\hline Partido Acción Popular & 14.406 & 4,91 \\
\hline Partido Aprista Peruano & 70.535 & 24,06 \\
\hline Agrupación Independiente Unión por el Perú- & 36.572 & 12,47 \\
\hline Social Democracia & 12.678 & 0,91 \\
\hline Todos por la Victoria & 13.660 & 4,66 \\
\hline Alianza Electoral Solución Popular & 68.414 & 23,33 \\
\hline Partido Perú Posible & 2.515 & 0,86 \\
\hline Partido Proyecto País & 4.820 & 1,64 \\
\hline Alianza Electoral Cambio 90-Nueva.Mayoría & 293.182 & \\
\hline Total votos válidos & 29.302 & \\
\hline \multicolumn{1}{l}{ Votos en blanco } & 32.815 & \\
\hline Votos nulos & 355.299 & \\
\hline Total votos emitidos & \\
\hline
\end{tabular}

\section{Distrito Electoral de Junin}

\begin{tabular}{lrc}
\hline & Total de votos & Porcentaje (\%) \\
\hline Alianza Electoral Unidad Nacional & 72.569 & 17,23 \\
\hline Frente Independiente Moralizador & 93.073 & 22,10 \\
\hline Frente Popular Agrícola FlA del Perú & 4.019 & 0,95 \\
\hline Movimiento Independiente Somos Perú & 22.138 & 5,26 \\
\hline Partido Renacimiento Andino & 9.425 & 2,24 \\
\hline Partido Acción Popular & 53.447 & 12,69 \\
\hline Partido Aprista Peruano & 40.701 & 9,66 \\
\hline Agrupación Independiente Unión por el Perú- & 2.157 & 0,51 \\
\hline Social Democracia & 2.874 & 0,68 \\
\hline Todos por la Victoria & 21.404 & 5,08 \\
\hline Alianza Electoral Solución Popular & 80.271 & 19,06 \\
\hline Partido Perú Posible & 3.623 & 0,86 \\
\hline Partido Proyecto País & 15.420 & 3,66 \\
\hline Alianza Electoral Cambio 90-Nueva Mayoria & 421.121 & \\
\hline Total votos válidos & 53.649 & \\
\hline$\quad$ Votos en blanco & 64.021 & \\
\hline$\quad$ Votos nulos & 538.791 & \\
\hline Total votos emitidos & \\
\hline
\end{tabular}




\section{Distrito Electoral de La Libertad}

\begin{tabular}{lrc}
\hline & Total de votos & Porcentaje (\%) \\
\hline Alianza Electoral Unidad Nacional & 72.815 & 12,75 \\
\hline Frente Independiente Moralizador & 20.475 & 3,58 \\
\hline Frente Popular Agrícola FIA del Perú & 6.635 & 1,16 \\
\hline Movimiento Independiente Somos Perú & 28.393 & 4,97 \\
\hline Partido Renacimiento Andino & 7.394 & 1,29 \\
\hline Partido Acción Popular & 17.352 & 3,04 \\
\hline Partido Aprista Peruano & 291.738 & 51,07 \\
\hline Agrupación Independiente Unión por el Perú- & & \\
Social Democracia & 4.177 & 0,73 \\
\hline Todos por la Victoria & 5.933 & 1,04 \\
\hline Alianza Electoral Solución Popular & 6.100 & 1,07 \\
\hline Partido Perú Posible & 94.924 & 16,62 \\
\hline Partido Provecto País & 4.295 & 0,75 \\
\hline Alianza Electoral Cambio 90-Nueva Mayoría & 11.057 & 1,94 \\
\hline Total votos válidos & 571.288 \\
\hline$\quad$ Votos en blanco & 58.787 \\
\hline$\quad$ Votos nulos & 57.925 \\
\hline Total votos emitidos & 688.000 \\
\hline
\end{tabular}

\section{Distrito Electoral de Lambayeque}

\begin{tabular}{lcc}
\hline & Total de votos & Porcentaje (\%) \\
\hline Alianza Electoral Unidad Nacional & 50.570 & 12,50 \\
\hline Frente Independiente Moralizador & 19.237 & 4,76 \\
\hline Frente Popular Agrícola FIA del Perú & 5.498 & 1,36 \\
\hline Movimiento Independiente Somos Perú & 19.415 & 4,80 \\
\hline Partido Renacimiento Andino & 12.745 & 3,15 \\
\hline Partido Acción Popular & 13.220 & 3,27 \\
\hline Partido Aprista Peruano & 120.964 & 29,91 \\
\hline Agrupación Independiente Unión por el Perú- & & \\
Social Democracia & 25.725 & 6,36 \\
\hline Todos por la Victoria & 1.518 & 0,38 \\
\hline Alianza Electoral Solución Popular & 15.944 & 3,94 \\
\hline Partido Perú Posible & 97.835 & 24,19 \\
\hline Partido Proyecto País & 12.673 & 3,13 \\
\hline Alianza Electoral Cambio 90-Nueva Mayoría & 9.114 & 2,25 \\
\hline Total votos válidos & 404.458 & \\
\hline \multicolumn{1}{l}{ Votos en blanco } & 43.756 & \\
\hline Votos nulos & 65.052 & \\
\hline Total votos emitidos & 513.266. \\
\hline
\end{tabular}




\section{Distrito Electoral de Lima}

\begin{tabular}{lrc}
\hline & Total de votos & Porcentaje (\%) \\
\hline Alianza Electoral Unidad Nacional & 529.448 & 14,71 \\
\hline Frente Independiente Moralizador & 425.669 & 11,83 \\
\hline Frente Popular Agrícola FIA del Perú & 50.085 & 1,39 \\
\hline Movimiento Independiente Somos Perú & 159.207 & 4,42 \\
\hline Partido Acción Popular & 77.714 & 2,16 \\
\hline Partido Aprista Peruano & 616.855 & 17,14 \\
\hline Agrupación Independiente Unión por el Perú- & 98.770 & 2,74 \\
\hline Social Democracia & 53.659 & 1,49 \\
\hline Todos por la Victoria & 121.065 & 3,36 \\
\hline Alianza Electoral Solución Popular & 1.061 .400 & 29,50 \\
\hline Partido Perú Posible & 59.341 & 1,65 \\
\hline Partido Proyecto País & 345.173 & 9,59 \\
\hline Alianza Electoral Cambio 90-Nueva Mayoría & 3.598 .386 & \\
\hline Total votos válidos & 336.136 & \\
\hline$\quad$ Votos en blanco & 414.234 & \\
\hline Votos nulos & 4.348 .756 & \\
\hline Total votos emitidos & \\
\hline
\end{tabular}

\section{Distrito Electoral de Loreto}

\begin{tabular}{lrc}
\hline Alianza Electoral Unidad Nacional & 15.890 & 7,21 \\
\hline Frente Independiente Moralizador & 24.910 & 11,30 \\
\hline Frente Popular Agrícola FIA del Perú & 4.422 & 2,01 \\
\hline Movimiento Independiente Somos Perú & 31.112 & 14,11 \\
\hline Partido Renacimiento Andino & 2.268 & 1,03 \\
\hline Partido Acción Popular & 9.302 & 4,22 \\
\hline Partido Aprista Peruano & 19.050 & 8,64 \\
\hline Agrupación Independiente Unión por el Perú- & & \\
Social Democracia & 21.958 & 9,96 \\
\hline Todos por la Victoria & 1.069 & 0,48 \\
\hline Alianza Electoral Solución Popular & 1.911 & 0,87 \\
\hline Partido Perú Posible & 86.172 & 39,09 \\
\hline Partido Proyecto País & 1.177 & 0,53 \\
\hline Alianza Electoral Cambio 90-Nueva Mayoria & 1.194 & 0,54 \\
\hline Total votos válidos & 220.435 & \\
\hline Votos en blanco & 21.281 & \\
\hline Votos nulos & 29.952 & \\
\hline Total votos emitidos & 271.668 & \\
\hline
\end{tabular}


17. Distrito Electoral de Madre de Dios

\begin{tabular}{lcc}
\hline & Total de votos & Porcentaje (\%) \\
\hline Alianza Electoral Unidad Nacional & 1.169 & 5,33 \\
\hline Frente Independiente Moralizador & 1.267 & 5,78 \\
\hline Frente Popular Agricola FIA del Perú & 327 & 1,49 \\
\hline $\begin{array}{l}\text { Movimiento Independiente Somos Perú- } \\
\text { Causa Democrática }\end{array}$ & 635 & 2,90 \\
\hline Partido Renacimiento Andino & 8.986 & 40,97 \\
\hline Partido Acción Popular & 1.226 & 5,59 \\
\hline Partido Aprista Peruano & 3.513 & 16,02 \\
\hline Todos por la Victoria & 234 & 1,07 \\
\hline Alianza Electoral Solución Popular & 276 & 1,26 \\
\hline Partido Perú Posible & 4.092 & 18,66 \\
\hline Partido Proyecto Pais & 87 & 0,40 \\
\hline Alianza Electoral Cambio 90-Nueva Mayoría & 122 & 0,56 \\
\hline Total votos válidos & 21.934 & \\
\hline$\quad$ Votos en blanco & 1.562 \\
\hline$\quad$ Votos nulos & 3.245 \\
\hline Total votos emitidos & 26.741 \\
\hline
\end{tabular}

\section{Distrito Electoral de Moquegua}

\begin{tabular}{lcc}
\hline & Total de votos & Porcentaje (\%) \\
\hline Alianza Electoral Unidad Nacional & 7.010 & 10,77 \\
\hline Frente Independiente Moralizador & 8.052 & 12,38 \\
\hline Frente Popular Agrícola FIA del Perú & 280 & 0,43 \\
\hline Movimiento Independiente Somos Perú & 7.792 & 11,98 \\
\hline Partido Renacimiento Andino & 359 & 0,55 \\
\hline Partido Acción Popular & 394 & 0,61 \\
\hline Partido Aprista Peruano & 6.123 & 9,41 \\
\hline Agrupación Independiente Unión por el Perú- & 19.709 & 30,29 \\
\hline Social Democracia & 103 & 0,16 \\
\hline Todos por la Victoria & 770 & 1,18 \\
\hline Alianza Electoral Solución Popular & 13.528 & 20,79 \\
\hline Partido Perú Posible & 941 & 1,45 \\
\hline Partido Proyecto País & 65.061 & \\
\hline Total votos válidos & 5.265 & \\
\hline$\quad$ Votos en blanco & 7.825 & \\
\hline Votos nulos & 78.151 & \\
\hline Total votos emitidos & & \\
\hline
\end{tabular}


19. Distrito Electoral de Pasco

\begin{tabular}{lcc}
\hline & Total de votos & Porcentaje (\%) \\
\hline Alianza Electoral Unidad Nacional & 7.906 & 10,13 \\
\hline Frente Independiente Moralizador & 7.965 & 10,21 \\
\hline Frente Popular Agrícola FIA del Perú & 1.522 & 1,95 \\
\hline Movimiento Independiente Somos Perú & 19.318 & 24,75 \\
\hline Partido Renacimiento Andino & 1.070 & 1,37 \\
\hline Partido Acción Popular & 6.543 & 8,38 \\
\hline Partido Aprista Peruano & 12.983 & 16,64 \\
\hline Agrupación Independiente Unión por el Perú- & & \\
Social Democracia & 1.690 & 2,17 \\
\hline Todos por la Victoria & 368 & 0,47 \\
\hline Alianza Electoral Solución Popular & 5.014 & 6,42 \\
\hline Partido Perú Posible & 12.994 & 16,65 \\
\hline Partido Proyecto País & 667 & 0,85 \\
\hline Total votos válidos & 78.040 & \\
\hline$\quad$ Votos en blanco & 8.544 & \\
\hline$\quad$ Votos nulos & 14.158 & \\
\hline Total votos emitidos & 100.742 & \\
\hline
\end{tabular}

\section{Distrito Electoral de Piura}

\begin{tabular}{lcc}
\hline & Total de votos & Porcentaje (\%) \\
\hline Alianza Electoral Unidad Nacional & 64.648 & 14,21 \\
\hline Frente Independiente Moralizador & 62.340 & 13,70 \\
\hline Frente Popular Agrícola FlA del Perú & 16.300 & 3,58 \\
\hline Movimiento Independiente Somos Perú & 65.040 & 14,30 \\
\hline Partido Renacimiento Andino & 15.848 & 3,48 \\
\hline Partido Acción Popular & 36.327 & 7,99 \\
\hline Partido Aprista Peruano & 119.929 & 26,36 \\
\hline Agrupación Independiente Unión por el Perú- & 22.564 & 4,96 \\
\hline Social Democracia & 9.960 & 2,19 \\
\hline Todos por la Victoria & 22.760 & 5,00 \\
\hline Alianza Electoral Solución Popular & 10.351 & 2,28 \\
\hline Partido Proyecto País & 8.859 & 1,95 \\
\hline Alianza Electoral Cambio 90-Nueva Mayoría & 454.926 & \\
\hline Total votos válidos & 144.482 & \\
\hline Votos en blanco & 73.491 & \\
\hline Votos nulos & 672.899 \\
\hline Total votos emitidos & \\
\hline
\end{tabular}




\section{Distrito Electoral de Puno}

\begin{tabular}{lcc}
\hline & Total de votos & Porcentaje (\%) \\
\hline Alianza Electoral Unidad Nacional & 33.571 & 9,00 \\
\hline Frente Independiente Moralizador & 39.916 & 10,71 \\
\hline Frente Popular Agrícola FIA del Perú & 23.493 & 6,30 \\
\hline Movimiento Independiente Somos Perú & 12.835 & 3,44 \\
\hline Partido Renacimiento Andino & 20.127 & 5,40 \\
\hline Partido Acción Popular & 41.025 & 11,00 \\
\hline Partido Aprista Peruano & 35.373 & 9,49 \\
\hline Agrupación Independiente Unión por el Perú- & 11.950 & 3,20 \\
\hline Social Democracia & 6.217 & 1,67 \\
\hline Todos por la Victoria & 17.150 & 4,60 \\
\hline Alianza Electoral Solución Popular & 121.004 & 32,45 \\
\hline Partido Perú Posible & 5.818 & 1,56 \\
\hline Partido Proyecto País & 4.386 & 1,18 \\
\hline Alianza Electoral Cambio 90-Nueva Mayoría & 372.865 \\
\hline Total votos válidos & 61.875 & \\
\hline \multicolumn{1}{l}{ Votos en blanco } & 85.421 & \\
\hline Votos nulos & 520.161 & \\
\hline Total votos emitidos & \\
\hline
\end{tabular}

\section{Distrito Electoral de San Martín}

\begin{tabular}{lcc}
\hline & Total de votos & Porcentaje (\%) \\
\hline Alianza Electoral Unidad Nacional & 28.340 & 16,11 \\
\hline Frente Independiente Moralizador & 12.244 & 6,96 \\
\hline Movimiento Independiente Somos Perú & 17.181 & 9,76 \\
\hline Partido Renacimiento Andino & 3.283 & 1,87 \\
\hline Partido Acción Popular & 7.889 & 4,48 \\
\hline Partido Aprista Peruano & 47.187 & 26,82 \\
\hline Agrupación Independiente Unión por el Perú- & 2.595 & 1,47 \\
\hline Social Democracia & 800 & 0,45 \\
\hline Todos por la Victoria & 19.231 & 10,93 \\
\hline Alianza Electoral Solución Popular & 33.420 & 18,99 \\
\hline Partido Perú Posible & 2.787 & 1,58 \\
\hline Partido Provecto Pais & 1.008 & 0,57 \\
\hline Alianza Electoral Cambio 90-Nueva Mayoría & 175.965 & \\
\hline Total votos válidos & 24.659 & \\
\hline$\quad$ Votos en blanco & 37.053 & \\
\hline$\quad$ Votos nulos & 237.677 & \\
\hline Total votos emitidos &
\end{tabular}




\section{Distrito Electoral de Tacna}

\begin{tabular}{lrc}
\hline & Total de votos & Porcentaje (\%) \\
\hline Alianza Electoral Unidad Nacional & 20.496 & 19,07 \\
\hline Frente Independiente Moralizador & 14.804 & 13,77 \\
\hline Movimiento Independiente Somos Perú & 3.903 & 3,63 \\
\hline Partido Renacimiento Andino & 781 & 0,73 \\
\hline Partido Acción Popular & 4.899 & 4,56 \\
\hline Partido Aprista Peruano & 15.263 & 14,20 \\
\hline Agrupación Independiente Unión por el Perú- & 10.074 & 9,37 \\
\hline Social Democracia & 5.197 & 4,83 \\
\hline Todos por la Victoria & 964 & 0,90 \\
\hline Alianza Electoral Solución Popular & 28.749 & 26,74 \\
\hline Partido Perú Posible & 1.149 & 1,07 \\
\hline Partido Proyecto País & 1.222 & 1,14 \\
\hline Alianza Electoral Cambio 90-Nueva Mayoría & 107.501 & \\
\hline Total votos válidos & 9.977 & \\
\hline$\quad$ Votos en blanco & 12.362 & \\
\hline Votos nulos & 129.840 & \\
\hline Total votos emitidos & \\
\hline
\end{tabular}

24. Distrito Electoral de Tumbes

\begin{tabular}{lrc}
\hline & Total de votos & Porcentaje (\%) \\
\hline Alianza Electoral Unidad Nacional & 5.540 & 8,77 \\
\hline Frente Independiente Moralizador & 2.948 & 4,67 \\
\hline Frente Popular Agrícola FIA del Perú & 218 & 0,34 \\
\hline Movimiento Independiente Somos Perú & 2.895 & 4,58 \\
\hline Partido Acción Popular & 11.883 & 18,80 \\
\hline Partido Aprista Peruano & 9.932 & 15,72 \\
\hline Agrupación Independiente Unión por el Perú- & 11.564 & 18,30 \\
\hline Social Democracia & 5.841 & 9,24 \\
\hline Todos por la Victoria & 1.751 & 2,77 \\
\hline Alianza Electoral Solución Popular & 8.257 & 13,07 \\
\hline Partido Perú Posible & 1.611 & 2,55 \\
\hline Partido Proyecto País & 751 & 1,19 \\
\hline Alianza Electoral Cambio 90-Nueva Mayoría & 63.191 & \\
\hline Total votos válidos & 5.523 \\
\hline Votos en blanco & 9.767 & \\
\hline Votos nulos & 78.481 & \\
\hline Total votos emitidos & \\
\hline
\end{tabular}




\section{Distrito Electoral de Ucayali}

\begin{tabular}{lcc}
\hline & Total de votos & Porcentaje (\%) \\
\hline Alianza Electoral Unidad Nacional & 15.988 & 15,14 \\
\hline Frente Independiente Moralizador & 12.805 & 12,13 \\
\hline Frente Popular Agrícola FIA del Perú & 3.110 & 2,95 \\
\hline Movimiento Independiente Somos Perú & 3.701 & 3,51 \\
\hline Partido Renacimiento Andino & 2.011 & 1,90 \\
\hline Partido Acción Popular & 2.592 & 2,46 \\
\hline Partido Aprista Peruano & 17.876 & 16,93 \\
\hline Agrupación Independiente Unión por el Perú- & 617 & 0,58 \\
\hline Social Democracia & 6.335 & 6,00 \\
\hline Todos por la Victoria & 2.975 & 2,82 \\
\hline Alianza Electoral Solución Popular & 34.858 & 33,02 \\
\hline Partido Perú Posible & 1.696 & 1,61 \\
\hline Partido Proyecto País & 1.014 & 0,96 \\
\hline Alianza Electoral Cambio 90-Nueva Mayoría & 105.578 & \\
\hline Total votos válidos & 13.588 \\
\hline$\quad$ Votos en blanco & 14.338 \\
\hline$\quad$ Votos nulos & 133.504 \\
\hline Total votos emitidos
\end{tabular}

De esta forma, el Congreso Unicameral quedaba con la siguiente conformación:

\begin{tabular}{lc}
\hline \multicolumn{1}{c}{ Partidos } & Curules \\
\hline Perú Posiamentarias \\
\hline Partido Aprista Peruano & 46 \\
\hline Alianza Electoral Unidad Nacional & 28 \\
\hline Frente Independiente Moralizador & 17 \\
\hline Unión por el Perú & 11 \\
\hline Movimuento Somos Perú-Causa democrática & 6 \\
\hline Acción Popular & 4 \\
\hline Alianza Cambio 90-Nueva Mayoría & 3 \\
\hline Todos por la Victoria & 3 \\
\hline Alianza electoral Solución Popular & 1 \\
\hline Partido Renacimiento Andino & 1 \\
\hline
\end{tabular}


La condena electoral a quienes representaban el antiguo régimen civicomilitar, era elocuente. De tener una ilegítima mayoría parlamentaria en el proceso electoral del 2000, quedaron reducidos a 4 representantes. Y si bien el partido del jefe del Ejecutivo había logrado cierta mayoría en el Congreso, ésta no era suficiente como goberrlar sin alianzas.

Ello ha propiciado que entre mayorías y minorias parlamentarias exista un estrecho diálogo, lo que se ha expresado no sólo con su respeto en el procedimiento legislativo, sino incluso en la conducción del Legislativo, que tiene como vicepresidentes a un representante de cada partido o movimiento con representación parlamentaria. 